\title{
Inovações organizacionais em política social: o caso da Grã-Bretanha ${ }^{1}$
}

Revista do

Serviço

Público

Ano 50

Número 3

Jul-Set 1999

\author{
Marcus André Melo \\ Nilson do Rosário Costa \\ Pedro Luís Barros Silva
}

\section{Introdução}

Este artigo discute o modelo de inovação no sistema de saúde introduzido na Grã-Bretanha nos anos 90, caracterizado pela implantação do mercado interno na atenção à saúde. Pelo seu pioneirismo, forte visibilidade internacional e intenso debate que suscitou, essa experiência é de grande valia para a discussão dos modelos de inovação em política de saúde. Ela é também paradigma de um dos pilares e/ou dimensões fundamentais da reforma de sistemas de saúde, qual seja a introdução de um modelo contratual, ancorado na separação entre provedor e comprador de serviços. Emblemática da segunda geração de reformas dos sistemas de saúde, que emerge nesse período em um conjunto amplo de países industrializados, contrasta fortemente com a chamada primeira geração, que foi impulsionada pelo imperativo macroeconômico de controle das despesas nacionais com a função saúde, caracterizando-se pelo foco organizacional e microeconômico (Guillen 1999; Saltman e Filgueiras 1998).

O texto a seguir reconstitui, rapidamente, a história da política de reforma do sistema de saúde, examina os mecanismos de ajuste introduzidos durante a implementação da reforma e discute os NHS trusts e GPs fundholders enquanto modelos organizacionais para sistemas de saúde.

\section{Antecendentes da reforma}

$\mathrm{O}$ modelo de mercado interno foi introduzido na Inglaterra por Thatcher em seu segundo mandato. ${ }^{2} \mathrm{~A}$ proposta esteve ancorada em

Marcus André Melo, doutor pela Sussex University e professor do Departamento de Ciência Política da UFPE.

Nilson do Rosário Costa, sociólogo, doutor em planejamento urbano e pesquisador titular da ENSP/ FIOCRUZ/RJ.

Pedro Luís

Barros Silva, administrador público, doutor em ciência política, professor do Instituto de Economia e coordenador do NEPP/ UNICAMP/SP 
dois movimentos fundamentais. O primeiro está associado à criação da

Comissão Interministerial que produziu um documento oficial, o White Paper Working for Patients, no qual se apresenta um amplo diagnóstico do National Health Service (NHS), e estabelecem-se diretrizes para uma reforma. O segundo movimento é representado pelas iniciativas práticas e conceituais em torno da idéia de mercado interno. Ambas, na realidade, precedem a proposta do governo Thatcher. No plano prático, várias iniciativas já incorporavam a idéia de mercado interno: na própria Inglaterra, a experiência de compra competitiva de serviços na área de East Anglia; na Holanda e na Nova Zelândia. No plano conceitual, por sua vez, as várias contribuições de Alan Enthoven, elaboradas durante a década de 80 , já estabeleciam as bases do modelo de mercado interno. ${ }^{3}$

Divulgado em 1989, Working for Patients consistiu em um amplo diagnóstico das mazelas que afligiam o NHS: graves problemas de financiamento, baixa qualidade de atendimento — sinalizada pelas longas filas de espera para tratamento hospitalar não-emergencial e profundas variações no padrão de atendimento entre as unidades do sistema. Vale assinalar que a primeira iniciativa importante do governo Thatcher ocorreu em 1983 através do Griffiths Report, ${ }^{4}$ que recomendou um conjunto de medidas gerenciais radicais na gestão do sistema, mas que na prática mantinha sua arquitetura geral intacta. $\mathrm{O}$ governo também formulou o Patients Charter em 1991 — estendendo os preceitos do Citizen's Charter para a área da saúde - sinalizando que o paciente era o foco do novo sistema.

Paradoxalmente, o governo Thatcher descartou iniciativas de mudança estrutural no sistema que implicasse em algum grau de privatização. Os documentos oficiais produzidos sancionam o modelo de pagador único (single payer) e financiamento público com recursos fiscais. Tendo firmado esta opção estratégica, a questão converteu-se em como introduzir mudanças no sistema, de forma a torná-lo mais eficiente no nível microeconômico. A questão macroeconômica ocupou pouco espaço na agenda, em virtude do próprio fato de que o gasto nacional em saúde na Inglaterra atingia um dos valores mais baixos entre os países da OCDE. ${ }^{5}$

A proposta de reforma foi aprovada no Parlamento em $1990^{6} \mathrm{e}$ começou a ser implementada em 1991. A principal mudança ocorrida relaciona-se à separação provedor-pagador no NHS. Antes da reforma, o NHS funcionava como um sistema integrado. A Figura e o Quadro 1 apresentam um sumário da situação antes e depois da reforma em relação aos papéis dos atores no sistema, os padrões de financiamento e gerenciamento, e a integração entre níveis de atenção. 
Criado em 1948, o NHS, antes da reforma em 1990, estava composto de 14 autoridades sanitárias regionais (RHA) na Inglaterra, mais escritórios provinciais no País de Gales, Escócia e Irlanda do Norte. Sob a supervisão direta dessas autoridades, encontravam-se as Autoridades de Saúde Distritais (DHAs), que encarregavam-se da operação de hospitais nas suas jurisdições. A rede hospitalar na Grã-Bretanha era e continua sendo de natureza predominantemente pública: mais de $80 \%$ dos leitos hospitalares estão em hospitais públicos.

\section{Figura 1: NHS - Organograma pós-reforma}

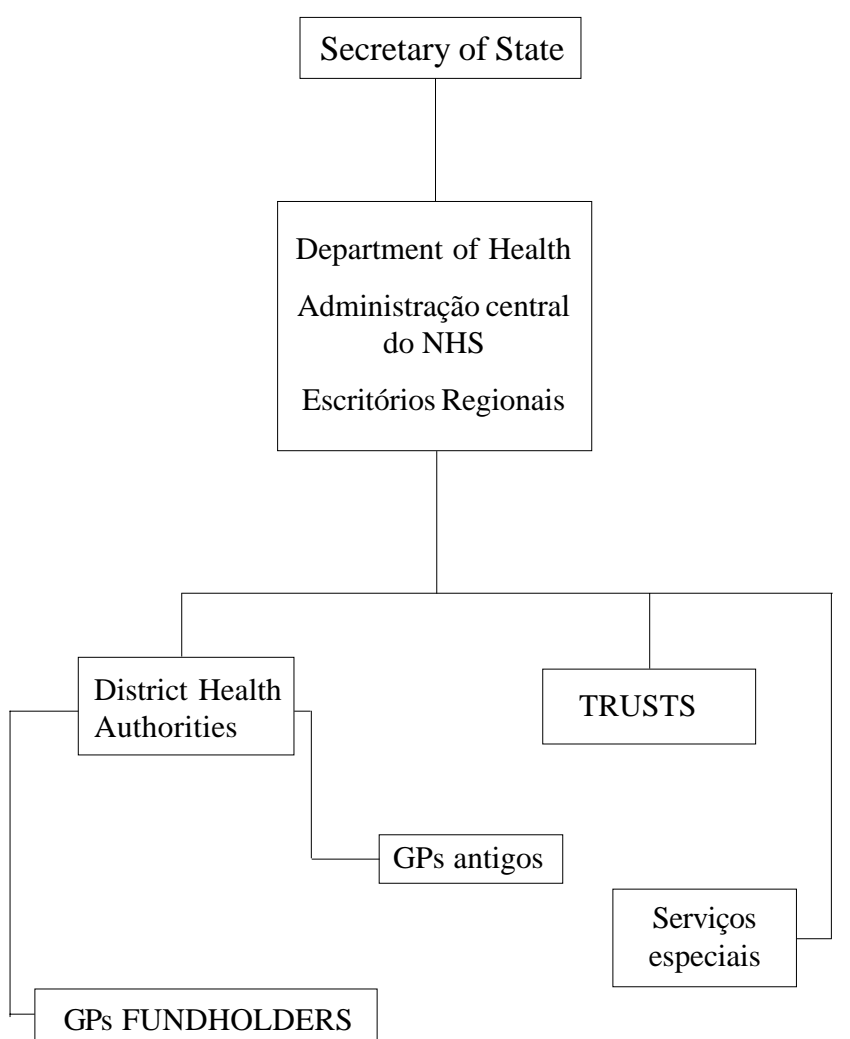


Quadro 1: O National Health Service

antes e depois da Reforma

\begin{tabular}{|c|c|}
\hline Antes da Reforma & Depois da Reforma \\
\hline \multicolumn{2}{|l|}{ Papel dos District Health Authorities } \\
\hline $\begin{array}{l}\text { Responsabilidades difusas envolvendo } \\
\text { o planejamento de serviços e a opera- } \\
\text { ção de hospitais e unidades de saúde. }\end{array}$ & $\begin{array}{l}\text { O DHA responsabiliza-se pela avaliação } \\
\text { das necessidade de saúde da população e } \\
\text { planejamento das ações de saúde. }\end{array}$ \\
\hline \multicolumn{2}{|l|}{ Financiamento dos serviços de saúde } \\
\hline $\begin{array}{l}\text { DHAs são financiados pelos serviços } \\
\text { prestados em suas jurisdições, com base } \\
\text { principalmente em histórico de fluxos } \\
\text { de pacientes. } \\
\text { Hospitais e outras unidades de saúde } \\
\text { recebem um orçamento de seus DHAs, } \\
\text { freqüentemente mantendo pouca relação } \\
\text { com o número de pacientes que irão } \\
\text { receber no próximo ano (devido à } \\
\text { distorção provocada pelos pacientes de } \\
\text { outros DHAs). }\end{array}$ & $\begin{array}{l}\text { DHAs são financiados para comprar servi- } \\
\text { ços de saúde em nome dos seus pacientes. } \\
\text { O financiamento reflete o tamanho, idade e } \\
\text { perfil da população de cada jurisdição. } \\
\text { Hospitais e outras unidades de saúde rece- } \\
\text { bem um orçamento de outros DHAs com os } \\
\text { quais eles estabeleceram contratos de presta- } \\
\text { ção de serviço. Os contratos estabelecem a } \\
\text { quantidade, qualidade e custo dos serviços a } \\
\text { serem prestados (em cada ano). O finan- } \\
\text { ciamento é, portanto, diretamente articulado } \\
\text { à prestação de um serviço específico. }\end{array}$ \\
\hline \multicolumn{2}{|l|}{ Gerenciamento dos serviços de saúde } \\
\hline $\begin{array}{l}\text { Grande número de níveis burocráticos } \\
\text { controlando as atividades dos hospitais } \\
\text { e outras unidades de saúde. }\end{array}$ & $\begin{array}{l}\text { Todos os hospitais e unidades de saúde assu- } \\
\text { mem maiores responsabilidades sobre suas } \\
\text { atividades, de forma que os indivíduos pres- } \\
\text { tando serviços são os mesmos que tomam as } \\
\text { decisões essenciais. Algumas dessas unida- } \\
\text { des tornam-se NHS trusts, independentes do } \\
\text { DHA, mas integrantes do NHS. }\end{array}$ \\
\hline \multicolumn{2}{|l|}{ Papel dos médicos generalistas (GPs) } \\
\hline $\begin{array}{l}\text { Poucos incentivos por parte dos hospi- } \\
\text { tais em responder e levar em conta as } \\
\text { preferências e necessidades dos pacien- } \\
\text { tes e médicos generalistas. }\end{array}$ & $\begin{array}{l}\text { DHAs consultam os GPs intensamente a } \\
\text { respeito do referenciamento (inclusive sobre } \\
\text { provedores preferenciais) e realizam surveys } \\
\text { sobre a qualidade de serviços como parte do } \\
\text { processo de contratação de serviços. } \\
\text { Alguns GPs tornam-se fundholders, pos- } \\
\text { sibilitando-lhes contratar os serviços dire- } \\
\text { tamente. }\end{array}$ \\
\hline \multicolumn{2}{|l|}{ Integração dos serviços de saúde } \\
\hline $\begin{array}{l}\text { Muito pouca integração entre atenção } \\
\text { primária e secundária, e pouca ênfase no } \\
\text { equilíbrio entre tratamento e prevenção. }\end{array}$ & $\begin{array}{l}\text { DHAs (responsáveis por serviços comuni- } \\
\text { tários de saúde de base hospitalar) e FHAs } \\
\text { (responsáveis pela atenção primária à famí- } \\
\text { lias) estão ambos sob a supervisão de uma } \\
\text { unidade regional (RHAs). O novo foco dos } \\
\text { DHAs na avaliação das necessidades de saúde } \\
\text { lhes permite lograr, conjuntamente com os } \\
\text { GPs, um melhor equilíbrio entre tratamento } \\
\text { e prevenção. }\end{array}$ \\
\hline
\end{tabular}

Fonte: Adaptado de Robinson (1994). 


\section{Mercado interno, quase-mercado ou mercado administrado?}

A principal modificação desejada pela reforma, ao separar provedores e compradores de serviço, foi transformar gerencialmente o sistema, instituindo uma estrutura competitiva que premia a eficiência e a qualidade. O financiamento dos DHAs (e, por extensão, dos hospitais que estavam em sua vasta maioria sob sua administração direta) passa com a reforma a ser feito através da compra de serviços realizados pelos trusts e GPs fundholders. É esse mercado de bens e serviços interno ao próprio setor público - portanto um quase-mercado - que determinará os preços, a qualidade e o volume de serviços de saúde.

O termo 'quase-mercado' representa um neologismo cunhado e difundido por um grupo de autores ingleses (Legrand e Bartlet, 1993) com relação a essas estruturas competitivas que emulam uma situação de mercado no seio do setor público. ${ }^{7} \mathrm{O}$ termo 'quase', mais precisamente, é justificado pelos seus proponentes por três razões, tanto pelo lado da demanda, quanto pelo lado da oferta. Pelo lado da oferta, há competição entre provedores de serviços, mas as entidades que participam desse mercado não são maximizadoras de lucro, nem são necessariamente privadas. Pelo lado da demanda, em um quase-mercado, o poder de compra não é monetizado. Ele toma a forma de orçamentos 'carimbados' (e que têm por definição um teto), sujeitos ao encontro de contas posteriormente, ou são vouchers só conversíveis em certos produtos específicos, ou está centralizado em uma agência governamental centralizada. Ademais, na maioria dos casos, a decisão de compra não está na mão do usuário ou consumidor final, mas em um segundo ator (GPs fundholders, care managers, DHAs etc.) ao qual se delega essa decisão.

$\mathrm{O}$ arranjo proposto pela reforma assenta-se no princípio de que com os contratos de serviços o dinheiro segue o paciente (money follows the patient). Essa noção representa um esforço de introduzir o conceito de soberania do consumidor em situações de concorrência perfeita, difundidas pela teoria econômica. Assume-se que, dessa forma, os provedores de serviço tenham um incentivo para responder mais efetivamente às necessidades dos pacientes. Esse é o pressuposto básico da separação comprador/provedor. ${ }^{8} \mathrm{O}$ resultado esperado é que se possa alterar o equilíbrio de forças em prol dos usuários de serviço em detrimento dos provedores, que, pela posição que ocupam, impõem seus interesses nos sistemas de provisão.

Uma qualificação importante, no entanto, é que, em princípio, os trusts e GPs fundholders podem comprar serviços de qualquer provedor, inclusive de provedores privados, embora o sistema tenha-se mantido, 
fundamentalmente, de propriedade pública (e os provedores privados têm se queixado de estarem em situação adversa). Nesse sentido, o sistema de facto representa um mercado interno, mas de jure seria melhor descrito como um sistema misto.

Os trusts representam os ofertantes de bens e serviços, e os GPs fundholders e DHAs representam os compradores de serviços. Esse arranjo já foi denominado por alguns autores como um modelo contratual monopsônico, e substitui o arranjo anterior caracterizado como um modelo integrado monopolista. O sistema é monopsônico porque tem um só conjunto de compradores públicos (Ham, 1997: 13). Não há competição pelo lado do financiamento do sistema (por terceiros pagadores ou seguradores).

Pelo lado da demanda, os recursos provêm de recursos fiscais, e são repassados para os DHAs e GPs fundholders com base em critérios populacionais (ajustados segundo parâmetros de idade, sexo, mortalidade e renda). ${ }^{9}$

Vale observar que, embora a adscrição rigorosa de clientelas seja mantida como base para o financiamento no novo modelo, rompeu-se o vínculo entre provedor e a população dentro de cada jurisdição. Essa ruptura ocorreu em outras áreas da política social, configurando o que Walsh et al.(1997) denominaram a revolução contratual na provisão de serviços sociais. ${ }^{10}$ No plano mais amplo do setor público como um todo, o novo paradigma foi anunciado pelo programa Next Steps e pelo Citizen's Charter.

$\mathrm{Na}$ área de serviços sociais, também introduziu-se a separação comprador-provedor. Foi instituída a figura do care manager que, conjuntamente, toma decisões sobre a compra de serviços de atenção domiciliar (a idosos, portadores de patologias de tratamento domiciliar, deficientes físicos, etc.) entre outros.

$\mathrm{Na}$ área educacional, que precedeu cronologicamente a reforma da saúde, introduziram-se vários modelos diferentes pelos quais as decisões relativas à alocação de recursos para as escolas passam a ser tomadas pelas famílias, substituindo decisões burocráticas por parte de entidades governamentais. ${ }^{11}$ No caso do sistema de vouchers — conhecido como open enrollments - as famílias de uma circunscrição recebem recursos (vouchers) a serem utilizados pelos seus estudantes para matricularemse em outra escola (o que não era permitido no modelo anterior). Nesse caso "o dinheiro segue o estudante." Observa-se uma interação mais próxima de uma situação de mercado, porque as escolhas de provedores (escolas) estão individualizadas e as decisões são tomadas pelas famílias.

No caso da saúde, as escolhas obedecem à avaliação das necessidades de saúde, em um distrito sanitário, realizada pelas DHAs, introduzindo-se, nesse caso, um elemento de planejamento que é estranho ao mercado. 
Afora os aspectos citados, também justificar-se-ia a qualificação de quase-mercado o fato de que, ao longo da implementação da reforma, muitos resultados ou situações de mercado foram objeto de interferência política e administrativa, porque foram julgados inaceitáveis (como foi o caso da situação potencialmente falimentar da maioria dos hospitais situados nas grandes conurbações inglesas como resultado da reforma). ${ }^{12}$ Nesses casos, os elementos de saída típicos de mercado — dentre os quais a pura falência de um provedor — não operam.

O sistema pós-reforma preserva, portanto, a universalidade do acesso à saúde, o financiamento público e introduz elementos que contribuem à competição administrada. A reforma pode ser considerada, portanto, como uma gigantesca iniciativa de planejamento - e não de reforma de mercado - , em bases conceituais novas, no âmbito do setor público. Ham (1997: 48), ${ }^{13}$ no entanto, assinala que devido à forte regulação pública do sistema, e devido ao fato de que hospitais privados podem participar do mesmo, esse seria melhor caracterizado como um modelo de mercado administrado.

Managed markets (mercado administrado), public competition (competição dentro do setor público), consumer choice-vouchers ${ }^{14}$ (modelo de escolha do consumidor), e quase-mercados, são expressões que designam alternativas distintas que variam, basicamente, em termos de quem pode participar (apenas entidades públicas, privadas, ONGs, empresas privadas ou um mix desses diversos agentes) da provisão de serviços, do desenho específico da política em relação à provisão de saúde — que, em todas as experiências de modelos competitivos de novo tipo, assentam-se no acesso universal.

Em relação a esse último ponto, os modelos universalistas podem ser divididos naqueles baseados no seguro ou em compra direta de serviços por terceiros. Três modelos podem, portanto, ser identificados: o modelo inglês, o modelo holandês (que combina acesso universal com o direito do cidadão de escolher ele próprio sua empresa de seguro saúde) e o modelo sueco (que combina acesso universal e competição entre provedores por serviços comprados por esferas locais de governo).

A matriz teórica dessas experiências, na realidade, é o modelo americano das Health Maintenance Organizations. Embora sejam instituições privadas, constituem-se em alternativas importantes para superar problemas que afligem mercados de seguro, como seleção adversa e moral hazard. A lição extraída dessas instituições, pelos modelos de saúde universal europeus, foi que entidades compradoras de serviço podem cumprir um papel importante em contrabalançar a influência dos provedores, ao mesmo tempo que também permitem eliminar problemas de moral hazard (o financiamento público e acesso universal podem, da mesma forma, levar ao superconsumo de serviços). 
Uma questão adicional para uma discussão sobre os quase-mercados

tem a ver com os requisitos e pré-condições para que eles funcionem e produzam os objetivos que se esperam dos mesmos (seja maior eficiência, responsiveness, liberdade de escolha, efetividade, ou equiidade).

Um dos aspectos essenciais é que o grau de monopólio no sistema (ou nas jurisdições) seja baixo. O argumento tradicional é que se os compradores podem organizar-se e exercer um forte poder de pressão, as ineficiências potenciais podem ser superadas ou reduzidas. Nessas situações, podem-se observar casos de monopólios bilaterais cuja solução também é ineficiente. Um dos supostos conceituais do modelo de mercado interno é a Teoria dos Mercados Constestáveis (contestable markets) ${ }^{15}$, que modela as condições nas quais mercados monopólicos podem ser eficientes pela mera existência ou ameaça de um competidor potencial, mesmo que essa ameaça não se realize na prática.

\section{Os trusts como modelo organizacional}

A reforma criou uma nova figura jurídica, os trusts, que foram criados a partir dos hospitais públicos existentes. À semelhança do que ocorreu com os DHAs, em virtude da redefinição de seu escopo de atividades, muitos trusts resultaram de fusões. Os trusts são entidades com fins não-lucrativos e não podem distribuir dividendos a seus controladores. Segundo Bartlett e Legrand (1994), mesmo no regime administrativo inglês, os trusts representam uma entidade de difícil categorização. Distinguemse de outras entidades desse tipo pelo fato de sua fonte de recursos não serem doações, mas a venda comercial de bens e serviços. No sistema anterior à reforma, os recursos produzidos pelos ganhos de eficiência logrados eram descontados do orçamento do ano subseqüente. Os ganhos de eficiência dos trusts podem ser retidos e apropriados pela entidade embora não possam ser convertidos em quaisquer formas de remuneração dos seus membros. Tais ganhos podem ser utilizados em melhorias na infraestrutura e treinamento dos seus membros, ou outras vantagens de caráter pessoal e/ou institucional.

Os trusts são entidades autônomas, do ponto de vista gerencial, embora seu diretor-executivo seja indicado pelo Secretary of State. A autonomia que gozam, deve-se, em grande parte, ao rompimento dos vínculos que os provedores mantinham com o nível distrital e regional da administração da saúde. Em certo sentido, os trusts assemelham-se a cooperativas de provedores de serviço. 
Os trusts são autônomos em matéria de recrutamento e remuneração (número de empregados a ser contratados; definição mix do staff; planos de cargos e carreira). No entanto, eles são fortemente regulamentados em relação às suas decisões de investimento de capital. Eles são sujeitos a limites rígidos de financiamento externo. Tais limites estabelecem restrições ao endividamento externo e à utilização de surpluses de caixa (especificando valores para repagamento de dívidas, etc). Os trusts também só podem desfazer-se de seus ativos ou adquirir novos dentro de alguns limites.

Em termos de sua gestão financeira, os trusts devem garantir que o uso de seus ativos produzam uma taxa de retorno de $6 \%$. Isso implica que, nos seus contratos, deve-se prever esta remuneração para os ativos em uso. Além disso, os trusts devem break even um ano com outro. Isso implica, basicamente, que seus preços devem ser equivalentes a seus custos médios, e que não pode haver subsídios cruzados entre serviços. Os trusts também devem manter-se dentro do seu limite de financiamento externo, sendo que investimentos de capital só podem ser realizados se os trusts demonstrarem que os custos podem ser cobertos com receita de contrato.

Essa forte regulação dos trusts significa, na prática, que a autonomia e independência deles é bastante limitada, e que uma perspectiva de curto prazo está embutida no seu regime financeiro. Tais limites à utilização dos excedentes gerados por uma gestão mais eficiente cancelam, em grande medida, os incentivos a uma melhor performance (Bartlett e Legrand, 1993: 56).

O Quadro 2 apresenta um conjunto de atributos dos trusts, comparados com o modelo de hospital diretamente administrado existente pré-reforma, segundo Kitchener (1998). Tais atributos referem-se a aspectos do modelo interpretativo dos provedores, dos sistemas de funcionamento e da estrutura organizacional. O modelo interpretativo consiste no conjunto de valores e normas que dão sustentação ao sistema e à estrutura de uma organização. 


\begin{tabular}{|c|c|}
\hline$O$ arquétipo do hospital pré-reforma & $O$ arquétipo do hospital pós-reforma \\
\hline \multicolumn{2}{|l|}{ O modelo interpretativo } \\
\hline $\begin{array}{l}\text { Atenção hospitalar organizada cooperati- } \\
\text { vamente e livre provisão. }\end{array}$ & $\begin{array}{l}\text { Atenção hospitalar organizada competitiva- } \\
\text { mente no âmbito de quase-mercados. Rela- } \\
\text { ções mercantis para garantir eficiência. }\end{array}$ \\
\hline $\begin{array}{l}\text { Ajustes estruturais baseados em aumentos } \\
\text { incrementais no financiamento. }\end{array}$ & Transformação. \\
\hline $\begin{array}{l}\text { Limites rígidos entre management e staff; } \\
\text { autonomia profissional. }\end{array}$ & $\begin{array}{l}\text { Limites frouxamente demarcados entre } \\
\text { management e staff; tentativas de redução } \\
\text { da autonomia profissional. }\end{array}$ \\
\hline $\begin{array}{l}\text { Um surplus orçamentário produzirá uma } \\
\text { redução do orçamento no ano subseqüente; } \\
\text { a atenção médica gera despesas; profis- } \\
\text { sionais bem-sucedidos consomem recursos; } \\
\text { a regulação determina o mix de serviços; } \\
\text { provisão de serviços na própria unidade } \\
\text { hospitalar. }\end{array}$ & $\begin{array}{l}\text { Um surplus orçamentário irá aumentar os } \\
\text { recursos disponíveis no ano subseqüente; a } \\
\text { atenção médica gera receita; profissionais } \\
\text { bem-sucedidos responsabilizam-se pela } \\
\text { orçamentação do consumo; os mercados } \\
\text { determinam o mix de serviços; tercei- } \\
\text { rização de serviços. }\end{array}$ \\
\hline \multicolumn{2}{|l|}{ Sistemas } \\
\hline $\begin{array}{l}\text { A renda manejada em cada unidade } \\
\text { provém das autoridades de saúde; } \\
\text { subsídios cruzados, ex: ensino médico } \\
\text { e serviços comunitários. }\end{array}$ & $\begin{array}{l}\text { A renda de cada trust provém de } \\
\text { contratos com as autoridades de saúde, } \\
\text { GPs fundholders e do setor privado. }\end{array}$ \\
\hline Sistemas de informação precários. & $\begin{array}{l}\text { Maiores necessidades de informação } \\
\text { de mercado. }\end{array}$ \\
\hline $\begin{array}{l}\text { A base de recursos da unidade é gerenciada } \\
\text { externamente; salários e recrutamento de } \\
\text { pessoal não são alteráveis no curto prazo; } \\
\text { decisões sobre fechamento ou mudanças } \\
\text { de uso na unidade são sujeitos a consultas } \\
\text { formais. }\end{array}$ & $\begin{array}{l}\text { A base de recursos é gerenciada interna- } \\
\text { mente. Não há necessidade de um trust } \\
\text { fazer consultas sobre fechamento ou } \\
\text { mudanças de uso na unidade. }\end{array}$ \\
\hline \multicolumn{2}{|l|}{ Estrutura } \\
\hline $\begin{array}{l}\text { Setorial - hierárquica e funcional, } \\
\text { baseada em comunicação vertical. }\end{array}$ & $\begin{array}{l}\text { Setorial - estruturas mais orgânicas e acha- } \\
\text { tadas quanto aos níveis hierárquicos; comu- } \\
\text { nicação baseada em rede; setor estruturado } \\
\text { segundo as especificações do contrato. }\end{array}$ \\
\hline $\begin{array}{l}\text { Interna - colegiados profissionais e } \\
\text { hierarquia administrativa. }\end{array}$ & $\begin{array}{l}\text { Interna - redes; diretorias clínicas } \\
\text { baseadas no cliente/mercado. }\end{array}$ \\
\hline
\end{tabular}

Fonte: Kitchener (1998).

As expectativas normativas em ambos os modelos são bastante distintas. O modelo trust está estruturado em bases competitivas, com baixa autonomia profissional, limites imprecisos entre management e staff, forte valoração simbólica da atenção aos custos por parte dos profissionais médicos e uma expectativa normativa de que pacientes produzam receita. 
Os trusts são sistemas gerenciados internamente, com estruturas exibindo forte compressão dos níveis hierárquicos, organização em rede e forte centralidade das novas diretorias clínicas.

A principal inovação organizacional dos trusts, em relação aos hospitais administrados diretamente pelos DHAs antes da reforma, foi a criação de clinical directorates, ou diretorias clínicas colegiadas. Tais diretorias envolvem diretamente profissionais médicos na tomada de decisão, em relação a assuntos gerenciais e administrativos (relativos a custo, volume e tipo de serviços).

Para Kitchener (1998), essas diretorias clínicas colegiadas produziram um certo isomorfismo organizacional ${ }^{16}$ nos provedores e representa o núcleo duro do que denomina modelo arquetípico dos trusts. Esse arranjo institucional surgiu em função da tensão entre os requisitos do modelo contratual e a preservação da autonomia médica. ${ }^{17}$

Harrison (1995: 168) descreve de forma concisa as implicações surgidas com a mudança organizacional ocorrida e suas implicações sobre a autonomia médica:

“... os trusts estão adotando formas internas de organização formal e orçamentos que buscam integrar os médicos especialistas, ${ }^{18}$ no gerenciamento geral das instituições. Todos os trusts têm um diretor médico, e muitos estão instituindo 'diretorias médicas' como seu princípio organizador básico. Essas diretorias são em geral baseadas em especialidades e são chefiadas por um médico que atua a metade do tempo como administrador, freqüentemente trabalhando em conjunto com um diretor geral não-médico. (...) A combinação dessas mudanças com um ambiente criado pela divisão comprador/provedor permitiu um controle gerencial muito maior sobre as atividades clínicas dos médicos do que a prevalecente anteriormente. Assim os gerentes de hospitais podem exigir mudanças em serviços clínicos com o argumento de que sem elas haverá perdas de receita."

O modelo de gestão transitou, portanto, daquilo que a literatura denominou de modelo de consenso para um modelo mais competitivo. Alguns elementos dessa nova forma de gestão foram introduzidos após as recomendações do Relatório Griffiths de 1983. Dentre as mudanças ocorridas, a principal foi a substituição de colegiados decisórios por uma estrutura mais centralizada em um gerente.

A transição para o modelo trusts seguiu um padrão, no entanto, no qual alguns arranjos anteriores foram mantidos. $\mathrm{Na}$ área de recursos humanos, por exemplo, concedeu-se a possibilidade dos servidores optarem por permanecer no modelo anterior, em termos de relações trabalhistas ou de 
aderir ao novo modelo (Seccombe e Buchan, 1995: 189). O modelo anterior estava assentado em negociações coletivas centralizadas e seguia o padrão conhecido como modelo dos Whitley Councils, ou seja, a adoção de uma arbitragem por comissões independentes, no caso de alguns profissionais. Esse modelo assentava-se na representação de empregados e empregadores em comissões nacionais por tipo de ofício. ${ }^{19}$

Fortemente centralizado, esse modelo manteve-se desde a criação do NHS em 1948 até a reforma, e funcionou de uma forma relativamente estável, em um dos setores mais intensamente sindicalizados, e no qual destacam-se sindicatos de grande força política, como o dos enfermeiros e auxiliares. Um dos efeitos da reforma, foi o de ter produzido, gradativamente, uma fragmentação desse modelo, onde as negociações trabalhistas são discutidas na própria unidade. Um dos pilares do modelo de consenso era o fato de que as negociações ocorriam de forma centralizada, em nível nacional, e não em nível distrital ou regional, despolitizando o gerenciamento.

No novo modelo, as negociações não são realizadas com os sindicatos, segundo grupos de ofício, mas estão assentadas na representação funcional de cada diretoria clínica (Seccomb e Buchan, 1995: 190-1). Os trusts mostravam-se inteiramente desaparelhados para o desempenho dessas funções e tiveram que, rapidamente, desenvolver capacidade institucional na área trabalhista, à semelhança de empresas de grande porte. A fragmentação da representação tem levado à abolição de aumentos salariais lineares e à introdução de sistemas de avaliação de desempenho.

Embora sua implementação tenha sido gradativa, é possível identificar claramente quem são os perdedores no plano dos provedores. Os estudos existentes têm destacado dois atores: os médicos de hospitais (pela perda de autonomia) e profissionais específicos, com grande perdas para os profissionais enfermeiros. A flexibilização de funções e tarefas que acompanhou a introdução do gerencialismo, acarretou perdas importantes para esse setor que, pela sua força política, havia desfrutado de prerrogativas consideráveis no modelo anterior.

Com relação aos profissionais médicos, Harrison (ibid.) assinala que:

“...os novos gerentes estão muito mais claramente "no comando’ das organizações provedoras. Dessa forma, os contratos dos médicos especialistas são gerenciados pelos trusts, os quais podem mais facilmente variar suas cláusulas. Por exemplo, há registro de vários trusts oferecendo contratos fixos de curto prazo, ao invés de contratos com estabilidade plena no emprego, além de incluírem outras restrições sobre a prática médica."

Um aspecto fundamental na nova estrutura organizacional pósreforma refere-se à mudança ocorrida na dinâmica da organização 
(Kitchener, 1998). Antes da reforma, os hospitais eram estruturas inteiramente voltadas para o seu próprio ambiente. Não dispunham de uma base informacional sobre o mercado, nem nenhuma preocupação com funções de marketing e comunicação externa. Os trusts, ao contrário, são estruturas voltadas para o seu ambiente externo.

Correlato a essa orientação, observaram-se um forte movimento de profissionalização da gestão e a introdução de sistemas de avaliação da satisfação do usuário. Um desenvolvimento perverso tem sido o uso de marketing agressivo junto a pacientes (Kitchener, 1998).

\section{O modelo organizacional dos GPs fundholders}

A pedra angular da reforma, da maneira em que ela originalmente foi desenhada, eram os distritos sanitários (DHAs), e não os GPs fundholders (Glennester, 1994: 9, passim). Os distritos é que funcionariam como grandes HMOs, comprando serviços em nome da população sob sua jurisdição direta. ${ }^{20}$ Gradativamente, e após muita controvérsia, os GPs fundholders passaram a constituir-se em elementos centrais do sistema, superando em importância estratégica os próprios DHAs (ibid.). Devido à baixa amplitude do pacote de serviços que um GP poderia responsabilizarse, estimava-se que mesmo que todos os GPs existentes tivessem se tornado fundholders, o valor agregado dos serviços equivaleria a apenas $15 \%$. Com as mudanças posteriores esse valor chegou quase a dobrar.

A reforma de 1990 redefiniu o papel dos médicos generalistas no NHS. Tais profissionais, devido ao mecanismo de adscrição de clientelas criado em 1948, representam os gatekeepers do sistema. Pela organização do sistema de referenciamento, eles continuam sendo a porta de entrada dos pacientes no sistema de saúde. Com as novas funções de gerenciadores de fundos, eles convertem-se efetivamente em operadores centrais do quase-mercado de serviços de saúde.

Do ponto de vista gerencial, os GPs fundholders desfrutam de grande autonomia. Eles passam a desfrutar de discrição quase total no plano das relações de trabalho: cobrem aspectos envolvendo salários e recrutamento de pessoal, podendo inclusive contratar gerentes para supervisionar as suas próprias practices (consultórios) e serviços de apoio.

Essa intermediação realizada pelo GP, que atua em nome do paciente, faz-se necessária em função do reconhecimento de que existem falhas de mercado importantes no mercado de serviços de saúde, sobretudo a assimetria de informação e moral hazard. Em outras palavras, durante o ato médico, é o profissional médico e não o paciente que determina o volume de serviços que deverá ser consumido. Na medida em 
que esse profissional não poderá, no arranjo proposto pela reforma, vender serviços ou lucrar com a demanda que ele controla e administra, e além do mais, podendo utilizar os recursos poupados pelo uso mais eficiente de recursos em benefícios para a sua practice, ${ }^{21}$ passa, assim, a defrontar-se com uma estrutura de incentivos que o faz agir efetivamente em nome do paciente.

Uma exceção, nesse quadro, são os casos de tratamento que podem ser realizados no próprio consultório, e que não são atenção primária, tais como pequenas cirurgias. Nesses casos, permitiu-se a criação de empresas operando na mesma unidade do consultório, de propriedade dos GPs, das quais os GPs poderiam comprar serviços. Esse modelo passou a ser denominado Private partnerships. Após vários experimentos com alguns casos, permitiu-se a generalização da prática, que, no entanto, é fortemente regulada. Os casos permitidos são restritos a apenas 17 categorias de tratamento, e os GPs só podem devotar 30 horas mensais a essas atividades (op. cit.: 16-7).

O papel dos GPs também é importante na redução dos problemas de moral hazard associada ao consumo de bens livres ou para o que se tenha contratado seguro. Os GPs operam, nesse caso, como uma barreira às tendências intrínsecas de superconsumo de serviços pelos pacientes em sistemas pré-pagos ou de financiamento livre. O papel de gatekeeper reduz essa tendência.

Por outro lado, os próprios GPs e não os pacientes podem se defrontar com um desincentivo a buscar alternativas de custo efetivas. No sistema pré-reforma, os GPs não tinham informações sobre os custos do tratamento hospitalar de seus pacientes e, por isso mesmo, tinham eles próprios o incentivo de encaminhar seus pacientes a especialistas. Como passam a dispor de um orçamento, essa estrutura de incentivos se inverte. O próprio GP passa a ser um elemento de contenção de custos. A sistemática de estabelecimento desse orçamento juntamente com o tipo de contrato que o GP estabelece com os provedores passam a ser as variáveis cruciais para a eficiência sistêmica do mesmo (Glennester et al., 1994; Legrand e Bartlett, 1993).

Durante a implementação da reforma, duas alternativas surgiram para estabelecer o tipo de orçamento dos fundholders (Glennester et al., 1994: cap. 9). O primeiro tipo baseava-se nos custos históricos das várias practices e regiões. $\mathrm{O}$ recurso à sua utilização justificava-se para que se assegurasse tranqüilidade na transição de um sistema a outro, sem interrupções de serviço que poderiam deslegitimá-la. O problema é que a manutenção das médias históricas existentes, que variavam fortemente de região a região, reproduzia o sistema anterior, e uma das suas principais mazelas: a enorme variedade de parâmetros de serviços e qualidade, e pouca sensibilidade dos GPs às questões de custos. Em outras palavras, os GPs 
continuariam a tratar os referenciamentos como um bem livre. Perversamente, esse sistema premiava os GPs que tinham custos maiores.

Uma alternativa seria o uso de médias desses custos. Mas com esse tipo de orçamentação pela média, os GPs acima da média tinham um incentivo a não aderir ao sistema de fundholding. Aqueles situados acima da média, supostamente mais eficientes, teriam um incentivo a aderir. Mas o problema, segundo a reforma, era justamente aqueles acima da média - os quais poderiam manter-se fora do sistema.

A segunda alternativa, o uso da capitação ponderada mostrou-se extremamente difícil de se operacionalizar, malgrado as várias tentativas feitas. ${ }^{22}$ Por isso, o NHS consagrou o uso da média histórica, mantendo a capitação por fórmula como meta de médio e longo prazo, mesmo sendo a primeira flagrantemente ineficiente (Glennester, 1994: 148-9). Era como se a implementação da reforma negasse na prática os seus ideais e objetivos. No período recente, introduziu-se um sistema de capitation benchmark que segundo Glennnester é:

“...defeituoso em sua construção, frouxamente determinado, e passível de manipulação. Ademais ele falha completamente em estabelecer quailquer parâmetro de 'necessidade', ou nível de financiamento, que reflita as características da população registrada em uma practice" (ibid.: 148).

Os contratos entre os GPs funholders e os provedores, por sua vez, podem ser de três tipos. O primeiro tipo são os chamados block contract. Nesses contratos especifica-se um valor anual, mas pago mensalmente, para o acesso livre de pacientes aos serviços dos provedores. Nesse caso, os provedores têm um incentivo a prestar menos serviços do que o esperado, e sua redução de serviços só pode ser constatada e ser objeto de negociação durante a renegociação anual do contrato. Nesse caso, o comprador não monitora os contratos detalhadamente, os custos administrativos são baixos e existem poucas condições de detectar infrações contratuais. $\mathrm{O}$ segundo tipo de contrato são os cost per case, no qual cada tipo de procedimento é pago à vista, sendo que o comprador tem que ter mais informações sobre os custos no mercado de serviços. O terceiro tipo de contrato são os chamados cost and volume, no qual se estabelece um volume mínimo de serviços a serem prestados e o fundholder repassa um valor mínimo mensalmente. Os serviços são monitorados detalhadamente. Os serviços prestados além do contratado são remunerados na base de cost per case, e os procedimentos não cobertos são objeto de renegociação. Se, alternativamente, o volume de serviços for menor do que o contratado, o provedor compensa essa defasagem restituindo recursos, ou prestando mais serviços no mês subseqüiente (Glennester et al., 1994: 101-2). 
Por questões operacionais, os fundholders utilizaram basicamente os blocks contracts, que são arranjos ineficientes. No período mais recente, há um recurso cada vez maior ao sistema de cost per case. Os GPs fundholders recebem recursos diretamente, na conta da instituição, para despesas correntes e de pessoal. Todos os pagamentos à rede contratada são realizados através de autorizações de pagamento enviadas pelos GPs à FHSA, que funciona como uma empresa de contabilidade, a qual, por sua vez, transfere os recursos diretamente à rede contratada, muitas vezes utilizando mecanismos contábeis de encontro de contas.

Os fundholders podem ter um incentivo a adotar práticas seletivas em relação a pacientes com perfis de risco mais altos, à semelhança de empresas de seguro. ${ }^{23}$ Alguns mecanismos foram instituídos para inibir tais práticas. Entre outras coisas, foi introduzida uma cláusula conhecida na literatura de seguro como stop loss. Por esse dispositivo, qualquer tratamento, que custe mais do que 5000 libras, tem seu custo arcado pelo DHA.

Um outro desenvolvimento indesejável, que poderia ocorrer possivelmente na nova estrutura de incentivos, seria uma tendência potencial de os GPs economizarem recursos — ou seja, disponibilizarem menor volume de tratamento aos pacientes, e, no limite, negarem o tratamento aos portadores de certas patologias, racionando serviços - para utilizarem tais recursos na própria unidade, em proveito de melhores condições de trabalho, ou para a atenção primária. O trade off que pode existir nesses casos é menos perverso do que aquele que ocorre em muitos sistemas, porque, pelo menos, ele ocorre basicamente sobre o uso de recursos entre níveis de atenção, e não sobre racionamento de recursos tout court. A proximidade dos GPs em relação a seus pacientes, o monitoramento das ações dos GPs pelas DHAs, a forte difusão da prática de auditagem médica no novo modelo (Harrison, 1995; Kerrison et al, 1994), e as pressões de ordem profissional são fatores importantes que contrarrestam essa tendência potencial.

A enorme adesão dos GPs ao novo sistema, no qual os GPs fundholders já representam a maioria, não foi antecipada pelos arquitetos da reforma. ${ }^{24}$ As barreiras à entrada no sistema de fundholding foram progressivamente sendo reduzidas. O número mínimo de pacientes necessários para a adesão ao status de fundholder foi reduzido, entre $1991 \mathrm{e}$ 1995, de 11.000 para 7.000 e finalmente para 3.000. ${ }^{25}$ Foi permitida também a associação de GPs com clientelas menores em multifunds. De forma semelhante, ocorreu uma expansão do tipo de serviços que poderiam ser comprados pelos GPs fundholders.

Em abril de 1996, o Department of Health lançou, em caráter experimental, o Total Purchasing Project. Cobrindo 87 localidades, o objetivo dessa iniciativa era de monitorar a experiência de implementação de GPs fundholders, aos quais concedeu-se total liberdade de compra de qualquer tipo de serviço em qualquer nível de atenção. Essa experiência 
está começando a ser avaliada por um grupo de trabalho, e suas conclusões ainda não estão disponíveis (Robinson e Steiner, 1998).

Em princípio, os GPs fundholders podem comprar serviços de qualquer provedor, inclusive de provedores privados, mas o sistema tem-se mantido, fundamentalmente, como sendo de propriedade pública. Estão excluídos do referenciamento as emergências médicas. Como assinalado, a força dos fundholders vai depender, principalmente, do grau de monopólio existente em nível dos provedores, e da capacidade dos GPs fundholders de demonstrar como articulam sua demanda, que, em princípio, é bastante fragmentada entre milhares de agentes. Há, no entanto, iniciativas de regulação do setor para evitar conluios e práticas não-competitivas. ${ }^{26}$

O novo modelo impactou a autonomia médica dos antigos GPs de várias formas. A autonomia médica tem sido discutida na literatura segundo três perspectivas: a) em primeiro lugar, como conceito que sanciona a hegemonia profissional dos médicos, e lhes garante benefícios e vantagens profissionais, em termos de tipo de tratamento empregado, mas também volume, estilo e logística de trabalho; b) em segundo lugar, como ética médica: a percepção de que o médico agirá no interesse do paciente e não de terceiros; c) em terceiro lugar, como mecanismo que dissimula politicamente o 'racionamento' de tratamento em sistemas que, pelo menos em teoria, garantem o acesso universal. ${ }^{27}$

Como assinalado na discussão do tópico anterior, o impacto dos trusts ocorreu sobretudo na forma do item a). O impacto do novo modelo de fundholding, por sua vez, ocorreu principalmente nas formas dos itens b) e c) referidas acima. Em primeiro lugar, o fato de os GPs passarem a responsabilizar-se pela compra de serviços, cria a possibilidade potencial de que estes possam ter interesses de natureza não-médica nos referenciamentos (ou no não-referenciamento). Muitos médicos entrevistados por Glennester et al. (1994: cap. 5) afirmaram sentirem-se constrangidos pelo fato de que, a partir da reforma, os pacientes teriam menos confiança em relação às decisões quanto às prescrições de remédios e referenciamento.

O julgamento clínico dos médicos pode também vir a ser entendido como julgamento social. ${ }^{28}$ Nos casos em que há restrições contratuais ao referenciamento, a visibilidade da perda de autonomia torna-se ainda mais expressiva. Associado a esse aspecto está a explicitação no novo modelo do papel do médico como racionador de recursos escassos. No caso dos trusts esse aspecto também está presente.

\section{Balanço das reformas}

Embora a experiência de reforma inglesa seja recente, é possível fazer algumas observações de natureza avaliativa. Um indicador 
relevante de que alguns avanços importantes ocorreram é o reconhecimento, pelo governo trabalhista de Tony Blair, de que a reforma está na direção correta. ${ }^{29}$

Fortemente identificada como uma proposta de um governo conservador radical, a avaliação da proposta foi prejudicada pela politização excessiva da discussão. Muitas melhorias, no entanto, podem não estar associadas diretamente à reforma e resultam do novo ambiente criado, em que as questões da saúde e, sobretudo, aquelas relativas à qualidade da atenção, ganharam grande centralidade e estavam ancoradas em decisões políticas que desfrutavam de forte e direto apoio do governo.

A avaliação do impacto da reforma, em termos de provocar maior eficiência no sistema mediante o aumento da competitividade adquirida no mercado interno criado, é relativamente inconclusiva. A força dos fundholders e DHAs (na compra de serviços de saúde pública) vai depender, fundamentalmente, do grau de monopólio existente em nível dos provedores. Algumas avaliações foram realizadas buscando-se aferir o grau de competição lograda no mercado interno da saúde criado pela reforma. Apleby et al. (1995) realizaram um estudo com dados de 1993 e estimaram que, para o caso específico de cirurgia geral na região central da Inglaterra (West Midlands), cerca de $75 \%$ dos hospitais não desfrutavam de posições potencialmente monopolísticas (medidas pelo índice de Hirschman-Herfindahl).$^{30}$ Os autores concluem, portanto, que o quasemercado criado é potencialmente competitivo. No entanto, a porcentagem daqueles que desfrutam de posições potencialmente monopolísticas (23\%) é preocupante para esses autores.

Outro estudo examinou, de forma detalhada, o efeito da nova competição nos trusts, com um foco no efeito do marco regulatório, em especial do sistema de preço médio adotado (Propper e Bartlett, 1997). As conclusões sugerem que os trusts exibem um comportamento bastante variado, evidenciando que são as variáveis de natureza organizacional e gerencial que explicam a heterogeneidade de situações encontradas. Os casos em que se observa maior devolução de decisões no controle gerencial "são aqueles mais inovadores e mais responsive às demandas dos GPs fundholder" (op cit.: 28).

Em relação ao efeito do novo sistema como resultado da introdução dos fundholders, Glennester et al. (1994: cap. 6) examinaram três tipos de contratos, correspondendo às três ondas pelas quais o sistema de fundholding foi implementado. As mudanças observadas variam segundo o tipo de contrato, mas são no conjunto positivas. Embora fossem bastante críticos da qualidade dos seus serviços, muitos GPs não mudaram os hospitais e especialistas com os quais mantinham referenciamentos, com receio de afetar relações estabelecidas. Há fortes evidências que a própria ameaça 
ou possibilidade de mudança, prevista pela Teoria dos Mercados Contestáveis, em relação a várias especialidades, influenciou o padrão de serviço vigente (ibid.).

Ocorreu efetivamente uma melhoria nos indicadores de eficiência sistêmica, como por exemplo, uma redução significativa no tempo de espera para cirurgias eletivas (embora tenha havido um aumento concomitante no número de pacientes esperando pelo serviço). É difícil, no entanto, atribuir esses ganhos de eficiência ao modelo de mercado interno. ${ }^{31}$ As melhorias ocorridas estão associadas à introdução de arranjos organizacionais mais eficientes para marcação de consultas e exames.

Uma das limitações aos ganhos do modelo de mercado interno tem sido o uso generalizado de contratos em bloco (block contracts), os quais não incorporam aspectos como qualidade ou produtividade. Nesses casos, inverte-se o princípio money follows the patient, pois é o "paciente que acaba seguindo o dinheiro" (Ham, 1997: 56; Harrison, 1995).

Parte substancial da eficiência do novo sistema, na prática, depende de como os contratos entre provedores e compradores têm sido desenhados e implementados (Flynn e Williams, 1997). Assim, o próprio uso ou não de certas cláusulas (ex. block contracts) cria situações distintas em termos do padrão de qualidade e volume de serviço efetivamente prestado.

A experiência desses contratos no NHS exibe uma extraordinária variabilidade, que tem a ver com as inúmeras contingências futuras nãoantecipadas e, fundamentalmente, pelo fato de que o sistema está em fase de implementação. Existem poucos casos de default contratual para informar como o descumprimento de cláusulas será tratado. Em resposta a essas situações, os contratos têm se tornado mais e mais detalhados (ibid.).

Outro aspecto crucial para definir o sucesso da reforma, como assinalado, tem a ver com a forma pelo qual as regiões específicas estabeleceram soluções para definir o orçamento de cada practice dos GPs fundholders. Há indicações de muita variação nesse sentido (Glennester, 1994: cap. 9 e 10). De qualquer forma, as áreas nas quais o sistema de fundholding opera - tratamento ambulatorial, cirurgias eletivas, serviços especializados, de patologia etc. - eram consideradas as mais notoriamente problemáticas e ineficientes de todo o NHS, de forma que, a despeito dos problemas de implementação, não foi muito difícil alcançar alguns ganhos de eficiência. A experiência de total purchasing, que busca emular o padrão managed care no caso inglês, ainda está sendo avaliada (Robinson e Steiner, 1998).

Uma das áreas com maior taxa de sucesso tem sido aquela relativa às práticas de prescrição de medicamentos. Os fundholders parecem ter uma consciência muito maior a respeito dos custos de medicamentos, e tem-se difundido o uso de genéricos com mais velocidade entre os fundholders do que entre os GPs tradicionais. 
Um dos aspectos que persistem como um dos problemas centrais do novo NHS refere-se às iniqüidades existentes no sistema, derivadas da existência de uma estrutura híbrida de fundholders e GPs tradicionais. Essas iniquiidades dizem respeito ao fato de que há mais recursos para certos tipos de tratamento para a população registrada nos fundholders do que para aquela registrada nos GPs tradicionais. Nesse último caso, as decisões de tratamento são tomadas pelos DHAs. No entanto, por várias razões, dentre as quais, o fato de que a orçamentação baseada no formula funding dos GPs leva em conta custos históricos e a dos DHAs não.

Outro aspecto importante relaciona-se aos custos de transação no novo sistema. O sistema de hospitais, diretamente administrados, tinha custos administrativos muito menores (Ham, 1997: 55). Novos recursos humanos foram contratados para as tarefas de administração dos centenas de milhares de contratos diferentes com GPs fundholders e DHAs. O novo sistema contratual de fato produziu uma crise administrativa no curto prazo e levou o governo a criar uma força-tarefa que produziu um conjunto de procedimentos racionalizadores. Com a criação de novas estruturas administrativas nas áreas de sistemas de informação e marketing, os custos do sistema aumentaram significativamente.

Em termos gerais, um aspecto consensual é que a reforma acarretou melhorias significativas na atenção primária (entrevista de David Johnson, 1998; e Ham, 1997). De fato, ocorreu um aumento muito expressivo no escopo dos serviços de atenção primária prestados pelos GPs, e nas ações de prevenção e saúde comunitária pelos GPs e DHAs. Em seu novo papel, os GPs fundholders ampliaram o número de profissionais de saúde trabalhando nas suas unidades (dentre os quais fisioterapeutas, nutricionistas, psicólogos etc.), estenderam o atendimento ambulatorial, além de terem atraído especialistas dos hospitais para prestarem atendimento nas próprias unidades dos GPs.

Um dos impactos mais visíveis ocorridos refere-se ao balanço geral entre a atenção hospitalar - nos setores dos acute hospitals mas também os hospitais universitários — e a atenção primária. Esse setor foi certamente o maior perdedor com a implantação da nova sistemática de financiamento baseada, estritamente, em critérios populacionais. Os acute hospitals localizam-se nas áreas centrais das grandes conurbações (Londres, Manchester, Glasgow, Birmingham, Liverpool etc.) que concentram uma população reduzida, e ademais, em declínio constante.

O caso de Londres foi suficientemente dramático pelo impacto que produziu (em hospitais de renome internacional como o St. Bartholomew's), tanto que criou-se um grupo de trabalho só para estudá-lo. Como as unidade de serviços deixaram de receber recursos, suas receitas declinaram abruptamente. 
O impacto das mudanças no complexo de interesses associados aos acute hospitals foi sumarizado por Ham (1997: p.54-5) nos seguintes termos:

"No NHS como um todo o impacto mais importante das reformas foi de alterar o equilíbrio de forças existente entre os vários interesses. Em termos organizacionais, as velhas estruturas hierárquicas integradas foram substituídas por um conjunto diversificado de arranjos contratuais. Nesses arranjos, o poder tradicional dos provedores, especialmente aqueles baseados nos acute hospitals, foi ameaçado. Isso foi possível pela transformação das autoridades de saúde de organizações orientadas para os provedores como compradores de serviços para a comunidade local. (...) As mudanças puseram em xeque a prioridade que tradicionalmente se conferiu aos serviços de atenção hospitalar e levou a um novo interesse na promoção da saúde, atenção primária e serviços comunitários”.

Uma das críticas importantes, a respeito do balanço entre atenção primária e hospitalar, é que, no limite, as mudanças ocorridas expressam o fato de que o novo NHS é mais responsive às demandas dos pacientes. Ham e outros autores assinalam que os GPs refletem as demandas dos pacientes mas não as necessidades de saúde da população. Essa última questão refere-se a aspectos mais amplos relativos à medicalização de orçamentos nos países industrializados.

\section{Conclusões}

O presente artigo discutiu o modelo de quase-mercado ou competição administrada introduzido no sistema de saúde inglês, nos anos 80 e 90, enquadrado na segunda geração de reformas do aparelho administrativo dos governos, caracterizando-se pelo enfoque organizacional e microeconômico. Compreende uma série de inovações representadas pelos incentivos à criação de um ambiente institucional favorável à melhoria da eficiência dos provedores de atenção, sejam elas públicas ou privadas. Esta segunda geração de reformas, portanto, tem desenhado novos papéis e relações para as agências e organizações públicas, estimulando a provisão de serviços por mecanismos de contratualização e pelo quase-mercado. A contratualização define, em bases formais, a separação entre financiamento e a provisão direta dos serviços. Embora seja ainda relativamente cedo para se avaliar tal reforma, pode-se verificar que a mesma pôs em xeque a centralidade tradicionalmente ocupada pelos serviços de atenção hospitalar e levou a um novo interesse na promoção da saúde, atenção primária e serviços comunitários. Como assinalado, muitas melhorias, no entanto, podem não estar associadas diretamente à reforma e resultam do 
novo ambiente criado em que as questões da saúde, e sobretudo aquelas

relativas à qualidade da atenção, adquiriram grande centralidade e passaram a estar ancoradas em decisões políticas, desfrutando de forte e direto apoio do governo.

Por sua vez, a avaliação do impacto da reforma, em termos de provocar maior eficiência no sistema por meio do aumento da competitividade adquirida no mercado interno criado é relativamente inconclusiva. Como assinalado, a força dos fundholders e DHAs (na compra de serviços de saúde pública) varia de acordo com o grau de monopólio existente ao nível dos provedores. Muitas das mudanças observadas variam segundo o tipo de contrato, mas são no conjunto positivas.

Ocorreu efetivamente uma melhoria nos indicadores de eficiência sistêmica, como por exemplo, uma redução significativa no tempo de espera para cirurgias eletivas, não podendo atribuirem-se esses ganhos de eficiência somente ao modelo de mercado interno. Uma das áreas com maior taxa de sucesso tem sido aquela relativa às práticas de prescrição de medicamentos.

Por outro lado, um dos aspectos que persiste como um dos problemas centrais do novo NHS refere-se às iniqüidades existentes no sistema derivadas da existência de uma estrutura híbrida de fundholders e GPs tradicionais, na qual há mais recursos para certos tipos de tratamento para a população registrada nos fundholders do que para aquela registrada nos GPs tradicionais. Outro aspecto importante relaciona-se aos custos de transação significativamente mais elevados no novo sistema.

\section{Notas}

1 Texto elaborado no marco do Projeto Reforma do Estado e o Setor Saúde, edital CAPES/ MARE, NEPP/UNICAMP-FIOCRUZ-UFPE.

2 Para uma reconstituição do processo inicial de reforma, cf. a interessante discussão de Butler (1994). Os termos Grã-Bretanha ou Inglaterra (ou inglesa) são utilizados indistintamente nesse capítulo em referência a essa experiência.

3 Cf. Enthoven (1978) e Enthoven (1985). Várias idéias associadas à adaptação do modelo HMO americano ao NHS já haviam sido discutidas por Alan Maynard, da York University, nos anos 80.

4 Griffiths (1983).

5 Cf. Ham (1997: 2-3).

6 A reforma foi implementada pelo National Health Service and Community Care Act, de 1990. 
7 O principal autor nessa linha é Julian Legrand. O conceito, no entanto, já foi utilizado sem muitas elaborações, pelos autores associados ao novo institucionalismo econômico (Williamson, 1975: 8).

8 Ou o split purchaser-provider, como veio a ser conhecido internacionalmente. Cf. Mays e Dickson (1997).

9 Segundo Glennester (1994: cap 9) e entrevista com David Johnson, a utilização desses critérios foi muito problemática e eles nunca foram implementados consistentemente, a despeito de várias tentativas realizadas.

10 Sobre esse tema cf. ainda Flynn, Williams e Pickard (1997).

11 Quatro inovações foram experimentadas : a) o open enrollment baseado em vouchers recebidos pelas famílias; b) o opting-out, pelo qual as escolas escolhem serem financiadas pelo Local Educational Authority ou pelo governo central (criando competição entre os dois níveis de governo e permitindo a uma boa escola escolher o melhor gestor), e adquirem autonomia quase total; c) oformula funding, pelo qual as escolas recebem recursos proporcionais aos estudantes que possam atrair (esteja no opting-out ou não); e, d) o local managed school, que também converte as escolas em gestoras autônomas de recursos proporcionais ao número de alunos. Cf. Bartlett (1993).

12 Esse ponto é retomado ao final do capítulo.

13 Segundo Ham (1997: 48) a única iniciativa efetiva do governo Thatcher no sentido da "privatização" da atenção à saúde foi a medida, criticada por membros do seu gabinete, permitindo o abatimento de gastos com seguro privado de saúde para os indivíduos com mais de 60 anos.

14 Para essas experiências, cf. Saltman e Otter (1995).

15 A teoria dos contestable markets está associada às contribuições do economista americano William Baumol.

$16 \mathrm{O}$ isomorfismo organizacional, na acepção consagrada do novo institucionalismo organizacional, refere-se à propensão das organizações, em um campo organizacional específico, a desenvolver normas, estruturas e sistemas similares. Ele resulta do mimetismo institucional — quando uma instituição emula padrões organizacionais de outras que julgam ser mais eficientes; quando organizações adotam uma forma organizacional, pela expectativa de legitimidade vis-à-vis seus provedores de recursos; ou pela influência de paradigmas cognitivos de organizações profissionais (cf. Di Maggio e Powell, 1983).

17 As implicações para os GPs fundholders são discutidas no tópico seguinte.

$18 \mathrm{Na}$ terminologia inglesa, o termo genérico para médico é physician; os médicos generalistas especializados na atenção primária são os GPs (general practitioners) e os especialistas são chamados de consultants. Nos Estados Unidos o termo genérico é clinician (termo cada vez mais usado na Inglaterrra), e os especialistas são chamados de consultants.

19 Essa representação reflete a organização sindical que, na Grã Bretanha, é estruturada por ofício (craft). Essa situação é inteiramente distinta de países como o Brasil, no qual os sindicatos do serviço público não são oficialmente reconhecidos. A permissão constitucional para a associação sindical após a Constituição de 1988 não foi até o presente regulamentada. Para uma análise comparativa da organização sindical no setor público brasileiro (cf. Cheibub, 1999).

20 A principal diferença é que as HMOs são, pelo menos nas suas variantes mais conhecidas (staff model e prepaid group practice ), sistemas integrados e não contratuais. (Robinson e Steiner, 1998: 10-11).

${ }^{21}$ Uma das áreas que mais benefícios trouxe para os GPs fundholders, entrevistados por Glennester et al. (1994), foi a de informática. Críticos do sistema dizem que esses recursos foram também investidos em reformas e ampliação das practices. Como em 
geral os GPs adquirem os estabelecimentos quando entram no sistema, e os revendem

22 A partir de vários modelos de regressão buscou-se, sem sucesso, estabelecer parâmetros para variáveis sócio-econômicas tais como taxa de desemprego.

23 Tais práticas são conhecidas na literatura sobre seguro médico como cream skimming (literalmente, retirar a nata do leite) — ou seja, selecionar os melhores riscos. Segundo Ham (1997: 60), no entanto, “as pesquisas até agora não encontraram evidências sistemáticas de seleção de risco ou cream skimming" (cf. também Glennester, 1994: cap. 9).

24 Cf. entrevista com David Johnson, 6 de maio de 1998; e Robinson (1994: 3.

25 Apenas $40 \%$ dos consultórios dos GPs tinham mais de 7.000 pacientes. A literatura americana sugeria que apenas HMOs com mais de 50.000 pacientes tinham um mix de riscos que as tornavam viáveis (Glennester, 1994).

${ }^{26}$ Ham (1997: 58). O monopólio desfrutado por um grande hospital em uma área específica relaciona-se ao seu raio de atendimento e à existência de outros provedores na área atendida.

${ }^{27}$ Além disso, a autonomia médica sanciona o tratamento individualizado de doenças que têm causação profissional ou sócio-ambiental clara, despolitizando-o (Harrison, 1995). Para esse tema, cf. New e Legrand (1996).

${ }^{28}$ Como nos casos de negação de cirurgias coronarianas em pacientes fumantes (que são discriminados em muitos países), mas não a pacientes obesos, quando as evidências sugerem uma diminuição similar da efetividade do procedimento em ambos os casos.

${ }^{29}$ Entrevista com David Johnson, em 6 de maio de 1998.

${ }^{30}$ Esse índice é utilizado pelo Departmento de Justiça americano para a sua política antitrust (Apleby, 1995: 44).

31 Essa é umas das áreas onde ocorreram forte monitoramento e pressão por parte das autoridades sanitárias, em virtude da enorme visibilidade pública desse problema.

\section{Referências bibliográficas}

Abel-Smith, B e Mossialos, E. (1994), "Cost Containment and Health Care Reform: a Study of the European Union". Health Policy, n. 28, (s. 1.).

APLeBY, J. et al. (1995), “Monitoring managed competition”, in Robinson, Ray and Legrand, Julian (1994), Evaluating the NHS reforms. Londres: King's Fund Institute, p. 24-52.

BARTLETT, Will e Legrand, Julian. (1994), "The performance of Trust funds", in Robinson, Ray and Legrand, Julian, Evaluating the NHS reforms. Londres: King's Fund Institute, p. 54-73.

BARTLETT, Will. (1993), "Quasi-markets and educational reforms", in Legrand, Julian and Bartlett, W. Quasi-markets and social policy. London: MacMillan, p. 125-152.

BUtLER, John. (1994), “Origins and early development”, in Robinson, Ray and Legrand, Julian (1994), Evaluating the NHS reforms. Londres: King's Fund Institute, p. 13-23.

CHeıвub, Zairo. (1999, no prelo ), "Reforma administrativa e relações trabalhistas no setor público: dilemas e perspectivas", Cadernos ENAP, n. 18. Brasília.

DiMAGGIO, P. e Powell, W. (1991), "The iron cage revisited: institutional isomorphism in and collective rationality in organizational fields", in Powell, W. e DiMaggio, P. The New Institutionalism in Organizational analysis. Chicago: The University of Chicago press. 
ENTHOVEn, Alan. (1978), "Consumer choice health plans: a national health insurance proposal based on regulated competition in the private sector". New England Journal of Medicine, 298, 709-20.

Enthoven, Alan. (1985), "Reflections on the Management of the National Health Service". Occasional Paper 5. Londres: Nuffield Provincial Hospitals Trusts.

FlynN, Rob e GARETH, Williams. (1997), Contracting for Health: quasi-markets and the National Health Services. Oxford: Oxford University Press.

Flynn, Rob, Gareth, Williams e PiCKard, Susan. (1997), Markets and Networks: contracting in Community Health Services. Buckingham: Open University Press.

GRIFFITHS, R. (1983), NHS management inquiry. Londres: DHSS.

GuILlÉN, Ana M. (1999), Improving Efficiency and Containing Costs: Health Care Reform in Southern Europe. Florence: Europe University Institute, Europe Forum.

HАм, Chris (ed.). (1997), Health Care Reform: learning from the international experience. Buckingham: Open University Press.

. (1997), "United Kingdom", in Ham, Chris (ed.), Health Care Reform: learning from the international experience. Buckingham: Open University Press, p. $46-62$.

. (1977), "The Background”, in Ham, Chris (ed.), Health Care Reform: learning from the international experience. Buckingham: Open University Press, p. $1-21$.

HARRISON, Stephen. (1995), "Clinical autonomy and planned markets: the British case", in Saltman, Richard and Von Otter, C. Implementing Planned markets in Health Care. Buckingham: Open University Press, p. 156-175.

KERRISON, Susan et al. (1994), "Monitoring medical audit", in Robinson, Ray and Legrand, Julian, Evaluating the NHS reforms. Londres: King's Fund Institute, p. 130-153.

Kitchener, Martin. (1998), "Quasi-market transformation: an institutionalist approach to change in UK hospitals". Public Management, v. 76, Spring, p. 73-95.

KLENNESTER, Howard et al. (1994), Implementing GP fundholding. Wild card or winning hand?. Buckingham: Open University Press.

LEGRAND, Julian e BARTLETt, W.. Quasi-markets and social policy. London: MacMillan.

Maynard, A e Bloor, K. (1996), "Introducing a Market to the United Kingdom's National Health Service". The New England Journal of Medicine. Massachusetts: Massachusets Medical Society, february.

MaYs, Nicholas e Dixon, Jennifer. (1996), Purchaser plurality in the UK health care. Londres: King's Fund Institute.

New, Bill e LEgRAND, Julian. (s.d.), Rationing in the NHS: principles and pragmatism. Londres: King's Fund Institute.

Propper, Carol e Bartlett, W. (1997), "The impact of competition on the behaviour of National Health Service Trusts", in Flynn, Rob and Williams, Gareth, Contracting for Health. Quasi-markets and the National Health Service. Oxford: Oxford University Press, p. 14-30.

Robinson, Ray e LEgRAND, Julian. (1994), Evaluating the NHS reforms. Londres: King's Fund Institute.

Robinson, Ray. (1994), "Introduction", in Robinson, Ray and Legrand, Julian, Evaluating the NHS reforms. Londres: King's Fund Institute.

Robinson, Ray e STEInER, Andrea. (1998), Managed Health Care: US evidence and Lessons for the National health Service. Buckingham: Open University Press.

Saltman, R. e Figueras, J. (1998), "Analysing the Evidence on European Health Care Reforms". Health Affairs, v. 17, n. 2, march/april.

Saltman, Richard e Von Otter, C. (1995), Implementing Planned markets in Health Care. Buckingham: Open University Press, p. 156-175. 
Otter, C. , Implementing Planned markets in Health Care. Buckingham: Open University Press, p. 134-155.

Seccombe, Ian e Buchan, J. (1995), “The changing role of the NHS personnel function", in Robinson, Ray and Legrand, Julian (1994), Evaluating the NHS reforms. Londres: King's Fund Institute, p. 178-207.

WALSH, Kieron et al. (1997), Contracting for Change. Contracts in Health, Social Care and other Local Government services. Oxford: Oxford University Press.

WiLliamson, Oliver. (1975), Markets and Hierarchies: analysis and antitrusts implications. London: The Free Press.

Entrevistas com:

David Johnson, North Essex Health Authority, Londres, 6 de maio de 1998 e Alan Maynard, junho de 1999, concedidas a Pedro Luís Barros Silva, Nilson Costa e Marcus Melo. 


\section{Resumo}

Resumen

Abstract

Revista do

Serviço

Público

Inovações organizacionais em política social: o caso da Grã-Bretanha

Ano 50

Número 3

Marcus André Melo, Nilson do Rosário Costa e Pedro Luís Barros Silva

Jul-Set 1999

O presente artigo discute o modelo de quase-mercado, ou competição administrada, introduzido no sistema de saúde inglês nos anos 80 e 90 . Essa experiência foi paradigmática da segunda geração de reformas dos sistemas de saúde, que emerge nesse período, e que contrasta fortemente com a chamada primeira geração, impulsionada pelo imperativo macroeconômico de controle das despesas nacionais com a função saúde. A segunda geração das reformas caracteriza-se pelo foco organizacional e microeconômico. O balanço da reforma é inconclusivo: enquanto alguns ganhos de eficiência foram conseguidos alguns aspectos continuam controversos - custos de transação maiores no novo sistema; iniqüidades entre os pacientes de GPs que aderiram à reforma e os que não aderiram —, além do fato de que os trusts desfrutam de poder de monopólio, limitando assim, os ganhos de eficiência perseguidos.

\section{Innovaciones organizacionales en política social: el caso de Gran Bretaña}

\section{Marcus André Melo, Nilson do Rosário Costa y Pedro Luís Barros Silva}

El presente artículo discute el modelo de casi-mercado, o competición administrada, introducido en el sistema de salud inglés de los años 80 y 90 . Esta experiencia fue paradigmática de la segunda generación de reformas de los sistemas de salud, que emergen en ese período, y que contrasta fuertemente con llamada primera generación, impulsada por el imperativo macro-económico de control de los gastos nacionales con la función salud. La segunda generación de las reformas se caracteriza por el foco organizacional y micro-económico. El balance de la reforma no es conclusivo: al mismo tiempo que se consiguió ganar eficiência en algunos aspectos, otros permanecen controvertidos - costeos de transacción más grandes en el nuevo sistema; iniquidades entre los pacientes de GPs que adherieron a la reforma y los que no adherieron —, además del hecho de que los "trusts"disfrutan de poder de monopolio, limitando así, los logros de eficiência buscados.

\section{Organisational innovations in social policy: the case of Great Britain}

Marcus André Melo, Nilson do Rosário Costa and Pedro Luís Barros Silva

This article discusses the reform of the British National Health System implemented in the 80s and 90s. This reform is paradigmatic of a new wave of reforms that affected a large number of industrialized countries in this decade. In sharp contrast with the first wave of reforms - in which the focus was cost containment and macroeconomic issues - this new wave emphasized microeconomic efficiency and organizational arrangements. The balance of the reform is mixed. While microeconomic efficiency has been improved, a number of issues remains open. These include the higher transaction costs, inequities between care for the patients in the system and those outside the new system, as well as the fact that the trusts still secure some monopoly power.
Marcus André Melo, doutor pela Sussex University e professor do Departamento de Ciência Política da UFPE.

Nilson do Rosário Costa, sociólogo, doutor em planejamento urbano e pesquisador titular da ENSP/ FIOCRUZ/RJ.

Pedro Luís

Barros Silva, administrador público, doutor em ciência política, professor do Instituto de Economia e coordenador do NEPP/ UNICAMP/SP 